\title{
Utilising CT data for assessing bone density
}

\author{
Joseph C. Lee ${ }^{1,2} \cdot$ Nikita Patel $^{3}$
}

Received: 22 August 2021 / Revised: 22 August 2021 / Accepted: 20 September 2021 / Published online: 28 September 2021 (c) ISS 2021

We commend Amin, Zakaria and Yahya [1] for attempting to determine the ideal location for assessing bone mineral density on computed tomography (CT) scans. There were three particular points we found interesting.

As they reviewed, a range of CT density values have been purported by various studies to predict osteoporosis. We are reticent regarding using data from a single site as BMD at one site alone may not be representative of the overall bone health status [2].

Further, we noted that they found that the hip CT data had the highest positive correlation with BMD. This contrasts with a widespread tenet that spine data is more consistent than hip data for follow-up as the precision error is generally lower here than at the hip site [3], and this has been found specifically also in CT assessments [4].

Most importantly, they emphasised the relationship between CT data and bone mineral density information specifically with regard to the diagnosis of osteoporosis. This underestimates the need to treat osteopenia-diagnosed by any modality, including CT. It is widely recommended that many measures can be undertaken to improve bone health even before the onset of osteoporosis and these discussions are freely available on the internet $[5,6]$. After all, a white woman - with osteopenia rather than osteoporosis-still has a $16 \%$ chance of fracture with a $T$-score of -1.0 . This escalates to $27 \%$ with a $T$-score of -2.0 and up to $33 \%$ with a $T$-score of -2.5 [5]. Can the authors provide guidance as to

This comment refers to the article available online at https://doi. org/10.1007/s00256-021-03801-z.

Joseph C. Lee

joseph.lee@health.qld.gov.au

1 Department of Medical Imaging, The Prince Charles Hospital, Chermside, QLD 4032, Australia

2 Faculty of Medicine, University of Queensland, Herston, Australia

3 University of Queensland Thoracic Research Centre, St Lucia, Australia what levels of CT density would be considered appropriate for management of osteopenia?

\section{Declarations}

Conflict of interest Dr. Lee has received travel expenses for attending meetings of his specialty at the College's Continuing Professional Development Committee, of which he is a member. He has received no other benefit (financial or non-financial) from this source. Dr. Patel has nothing to disclose.

\section{References}

1. Amin MFM, Zakaria WMW, Yahya N (2021) Correlation between Hounsfield unit derived from head, thorax, abdomen, spine and pelvis CT and t-scores from DXA [published online ahead of print, 2021 May 22]. Skeletal Radiol https://doi.org/10.1007/ s00256-021-03801-z

2. Sahota O, Pearson D, Cawte SW, San P, Hosking DJ. Site-specific variation in the classification of osteoporosis, and the diagnostic reclassification using the lowest individual lumbar vertebra T-score compared with the L1-L4 mean, in early postmenopausal women. Osteoporos Int. 2000;11(10):852-7. https://doi.org/10. 1007/s001980070044.

3. Lee JC, Loh NK. Frequently asked questions on measurement of bone mineral densitometry. J Prim Health Care. 2012;4(3):259-61.

4. Nwachukwu BU, Schreiber JJ, Lorich DG, Lane JM. Opportunistic use of CT imaging for osteoporosis screening and bone density assessment: a qualitative systematic review. J Bone Joint Surg Am. 2017;99(18):1580-90.

5. Harvard Health Publishing. "Osteopenia: When you have weak bones, but not osteoporosis". 2020. Available from: https://www. health.harvard.edu/womens-health/osteopenia-when-you-haveweak-bones-but-not-osteoporosis. Accessed 20 Aug 2021.

6. Healthline. "What is Osteopenia?" 2019. Available from: https:// www.healthline.com/health/osteopenia. Accessed 20 Aug 2021.

Publisher's note Springer Nature remains neutral with regard to jurisdictional claims in published maps and institutional affiliations. 